\title{
Pasak Customized Fiber Reinforced Composite Indirect pada Gigi Incisivus Lateralis Kiri Atas dengan Dinding Saluran Akar yang Tipis
}

\author{
Monika Prima Dewi Ayuningtyas Subroto*, Ema Mulyawati* ${ }^{* *}$ dan Pribadi Santosa** \\ *Program Studi Konservasi Gigi, Program Pendidikan Dokter Gigi Spesialis Fakultas Kedokteran Gigi, Universitas Gadjah Mada, \\ Yogyakarta, Indonesia \\ **Bagian Konservasi Gigi, Fakultas Kedokteran Gigi, Universitas Gadjah Mada, Yogyakarta, Indonesia \\ *JI Denta No. 1 Sekip Utara, Yogyakarta, Indonesia; e-mail: monque_dentz@yahoo.com
}

\begin{abstract}
ABSTRAK
Gigi pasca perawatan saluran akar (PSA) biasanya mengalami kehilangan struktur gigi yang luas oleh karena karies, faktor iatrogenik, restorasi sebelumnya dan fraktur. Pengurangan dentin di dalam saluran akar akan menyebabkan saluran akar menjadi tipis, sehingga restorasi konvensional dengan pasak logam dapat menyebabkan fraktur akar. Untuk meminimalkan fraktur akar tersebut, telah dikenal pasak fiber yang memiliki modulus elastisitas yang sama dengan dentin. Pada saluran akar yang lebar dan ireguler serta struktur mahkota yang minimal, dibutuhkan pasak customized fiber reinforced composite dengan inti yang dapat memperkuat struktur gigi yang sudah lemah. Studi kasus ini melaporkan kasus restorasi gigi non vital pasca PSA dengan dinding saluran akar tipis, yang berhasil dirawat dengan customized fiber reinforced composite indirect. Seorang pasien wanita usia 27 tahun dirujuk ke Bagian Konservasi Gigi karena mengalami over instrumentasi saluran pasak pada gigi incisivus lateralis kiri atas. Pada pemeriksaan radiograf, tampak dinding saluran akar sangat tipis. Restorasi ini dilakukan dalam 3 kali kunjungan. Pada kunjungan pertama dilakukan pencetakan saluran pasak dengan teknik double impression. Pasak customized fiber reinforced composit indirect, dibuat dalam cetakan saluran pasak menggunakan resin komposit Premise Indirect (Kerr) yang diperkuat dengan pita fiber (Construct, Kerr). Inti dan pasak yang sudah dibentuk, disinar menggunakan Light Cure selama 20 detik di setiap sisi, lalu polimerisasi disempurnakan dengan oven selama 20 menit. Pada kunjungan kedua dilakukan insersi pasak dan pencetakan mahkota jaket dengan teknik double impression. Pada kunjungan ketiga dilakukan insersi mahkota jaket. Gigi non vital pasca PSA dengan dinding saluran pasak yang tipis dapat direstorasi dengan customized fiber reinforced composite indirect dengan baik.
\end{abstract}

Maj Ked Gi Ind. Juni 2015; 1(1): 109-114

Kata kunci: Gigi non vital, dinding saluran akar tipis, customized fiber reinforced composite indirect

\begin{abstract}
Indirect Customized Fiber Reinforced Composite Post In Upper Left Lateralis Incisivus With ThinWalled Root. Excessive tooth structure loss after root canal treatment is usually present due to caries lesion, iatrogenic factor, previous restoration, and fracture. Intra-radicular dentin removal during root canal treatment may result in thin root canal wall structures, therefore conventional restoration using metallic post frequently leads to irreparable root fractures. In order to minimize the root fracture risk, fiber post has been known as an ideal choice because of its similar modulus elasticity characteristic to dentin. The wide and irregular root canal accompanied with minimum remaining tooth structure needs a customized fiber reinforced composite post to strengthen the preserved tooth structure. This article reports a succesful restoration of a non vital post root canal treatment tooth with thin root canal walls using indirect customized fiber-reinforced composite post. A 27-year-old female patient with over instrumentation in root canal of the upper left lateral incisor was referred to the Department of Conservative Dentistry. The radiograph examination finds that there was a very thin wall of the remaining root canal structure. The restoration was carried out in 3 visits. In the first visit, post canal impression was obtained using double impression technique. Indirect customized fiber reinforced composite post was made in the mold using composite resin Premise Indirect (Kerr) reinforced with fiber band (Construct, Kerr). The formed post and core were light cured for 20 seconds, and then refined by oven polymerization for 20 minutes. In the second visit, the post was inserted and crown impression was obtained using double impression technique. In the third visit, the jacket crown was inserted. The root canal treated tooth with remaining thin post canal wall could be restored with indirect customized fiber reinforced composite. Maj Ked Gi Ind. Juni 2015; 1(1): 109-114
\end{abstract}

Keywords: Non vital tooth, thin root canal wall, indirect customized fiber reinforced composite

\section{PENDAHULUAN}

Dalam klinik sering ditemukan gigi pasca perawatan saluran akar (PSA) yang mengalami kehilangan struktur gigi cukup banyak baik pada bagian mahkota maupun akarnya. Struktur gigi yang lemah disertai saluran akar yang tipis, merupakan 
akibat dari perluasan karies, trauma gigi immatur, patosis pulpa, ataupun faktor iatrogenik. ${ }^{1}$ Gigi pasca PSA cenderung memiliki struktur yang lemah oleh karena karies dan atau restorasi sebelumnya, fraktur atau trauma, akses endodontik dan instrumentasi, serta menurunnya kelembaban. ${ }^{2}$ Dentin menjadi lebih getas oleh karena hilangnya kelembaban atau hilangnya jaringan pulpa pada gigi non vital. ${ }^{3}$ Saluran akar yang tipis tidak dapat menahan kekuatan mastikasi dan rentan terjadi fraktur. ${ }^{4}$

Restorasi gigi pasca PSA umumnya menggunakan restorasi intraradikular atau inti pasak yang dapat memperkuat bagian koronal gigi. ${ }^{1}$ Dalam beberapa tahun, pasak logam digunakan untuk perawatan gigi dengan saluran akar lebar tanpa melihat kualitas dan kuantitas jaringan gigi yang tersisa. Pasak custom logam presisi di dalam saluran akar, tetapi memiliki potensi untuk menyebabkan fraktur karena logam memiliki sifat kekakuan yang tinggi. Oleh karena alasan tersebut, pasak fiber meningkat popularitasnya karena memiliki sifat biomekaniknya yang baik dan dapat menurunkan insidensi fraktur akar. ${ }^{4}$

Pengenalan pasak fiber dalam Kedoteran Gigi restoratif, memiliki dampak yang baik dalam merestorasi gigi pasca PSA. ${ }^{1}$ Pasak fiber memiliki modulus elastisitas yang sama dengan dentin, mudah diambil kembali jika dibutuhkan retreatment, dan bersifat estetik. ${ }^{5}$ Pasak fiber tidak hanya berperan dalam meminimalkan resiko fraktur akar, tetapi juga meningkatkan hasil yang estetik pada restorasi koronal. Pasak fiber dipercaya dapat mendistribusikan tekanan lebih merata pada gigi, dibandingkan dengan pasak logam yang membuat gigi rentan terhadap fraktur. ${ }^{7}$ Pasak fiber prefabricated memiliki adaptasi yang optimal pada gigi dengan saluran akar yang kecil dan sirkular. Pada saluran akar yang lebar dan ireguler, pasak ini tidak diindikasikan karena adaptasinya kurang baik dan membutuhkan semen resin yang cukup tebal. ${ }^{5}$ Adaptasi pasak dalam saluran akar merupakan elemen penting dalam biomechanical performance pada restorasi prostetik. Retensi dan adaptasi pasak fiber dapat meningkat secara signifikan apabila dibuat customized, sehingga didapatkan pasak fiber yang menyesuaikan morfologi saluran akar. ${ }^{1}$ Laporan kasus ini menjelaskan tentang prosedur perawatan gigi non vital pasca PSA dengan dinding saluran akar yang sangat tipis oleh karena over instrumentasi saluran pasak. Dalam naskah publikasi ini, pasien sudah menyetujui bahwa kasusnya akan dipublikasikan untuk kepentingan ilmu pengetahuan.

\section{METODE}

Pasien perempuan berusia 27 tahun datang ke klinik Konservasi Gigi RSGM Prof. Soedomo FKG UGM ingin melanjutkan perawatan gigi depan kiri atas yang sebelumnya sudah dirawat oleh koass. Pasien dirujuk ke klinik residen karena terdapat kesalahan selama prosedur perawatan yaitu terjadi over instrumentasi saluran pasak. Pada pemeriksaan objektif, gigi 22 terdapat kavitas pada bagian mesio-insisal dengan kedalaman profunda (Gambar 1). Hasil tes perkusi dan palpasi negatif. Pada pemeriksaan radiografis, terlihat dinding saluran akar sudah tipis akibat preparasi saluran pasak yang berlebih. Tampak sisa guta perca kurang lebih $5 \mathrm{~mm}$, saluran akar sedikit membengkok ke arah distal, serta tidak tampak adanya area radiolusen di daerah periapikal gigi 22 (Gambar 2).

Diagnosis kasus ini adalah gigi 22 non vital pasca PSA. Rencana perawatannya adalah restorasi mahkota jaket komposit dengan pasak customized fiber reinforced composite indirect. Prognosis dalam kasus ini baik, karena gigi memiliki saluran akar tunggal, struktur jaringan pendukung gigi masih baik, tidak terdapat lesi periapikal, asimptomatik, dan pasien kooperatif.

Pada kunjungan pertama, pasien menandatangani informed consent sebelum dilakukan perawatan. Preparasi mahkota jaket dilakukan secara garis besar pada bagian mahkota gigi 22 . Preparasi permukaan insisal menggunakan bur intan round wheel. Preparasi permukaan fasial dan palatal menggunakan bur torpedo. Preparasi permukaan proksimal menggunakan bur torpedo dengan kemiringan dinding aksial maksimal $6^{\circ}$. Semua email yang tidak didukung dentin dihilang- 
kan. Semua sudut preparasi dibulatkan dan semua permukaan preparasi dihaluskan dengan bur intan kekasaran superfine. Setelah itu dibuat kontra bevel di sekeliling preparasi (cavosurface) dengan bur diamond bentuk nyala api membentuk semacam kerah (collar), dengan tujuan untuk mencegah gigi yang dipegang supaya tidak fraktur, juga untuk ketepatan pengepasan pasak, hubungan tepi inti dan struktur jaringan gigi yang tersisa baik.

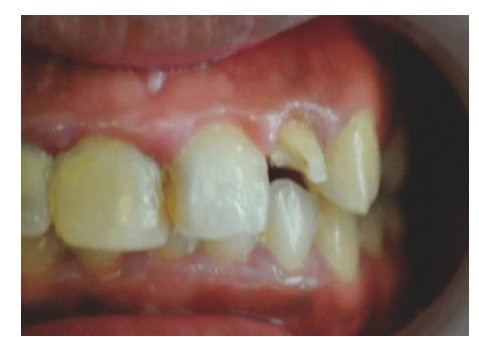

Gambar 1. Gigi 22 terdapat kavitas pada bagian mesio-insisal dengan kedalaman profunda.

Perhitungan panjang pasak dilakukan pada gigi 22. Panjang kerja $21 \mathrm{~mm}$ sedangkan panjang mahkota klinisnya adalah $8 \mathrm{~mm}$. Panjang pasak yang direncanakan masuk ke dalam saluran akar adalah $8 \mathrm{~mm}$. Panjang pasak ini telah memenuhi syarat yaitu dua per tiga dari panjang akar atau sama dengan panjang mahkota klinis sehingga guta perca pada bagian apikal yang tersisa kirakira $5 \mathrm{~mm}$. Pada radiograf, panjang pasak yang akan dibuat sudah memenuhi persyaratan panjang pasak, hanya perlu dilakukan sedikit pengambilan guta perca sisi mesial menggunakan hot endodontic plugger, kemudian dilakukan Rontgen foto.

Saluran akar diirigasi dan dikeringkan dengan paper point steril kemudian dilakukan pencetakan saluran pasak dengan bahan cetak double impression pada rahang atas dan pencetakan rahang bawah dengan irreversible hydrocolloid. Hasil cetakan diisi dengan hard stone gips dan diilakukan pemasangan mahkota sementara pada gigi 22.

Pasak customized fiber reinforced composite indirect dibuat sendiri oleh operator. Tahap pertama, model kerja diberi lapisan separating medium (latex/rubber sep) pada saluran pasak serta mesial dan distal gigi 22. Pita fiber construct (Kerr) lebar $1 \mathrm{~mm}$ dipotong dengan panjang 3 kali saluran pasak yang akan dibuat. Pita fiber dioles tipis dengan flowable resin construct warna transparan (light). Composite primary dentin (Indirect composite) disiapkan kemudian digulung dan dibentuk seperti pasak dengan spatel, setelah

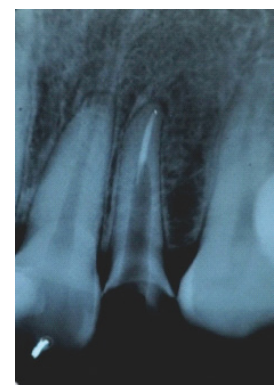

Gambar 2. Pada gambaran radiografis, tampak dinding saluran pasak sangat lebar akibat over instrumentasi.

itu dimasukkan ke dalam saluran pasak. Pita fiber dijepit bagian tengahnya dan dimasukkan ke saluran pasak, lalu dimampatkan dengan plugger. Bila perlu, tambahkan composite primary dentin untuk membentuk bangunan inti, lalu disinar dengan Light Curing selama 20 detik di setiap sisi. Model kerja beserta pasak dimasukkan dalam oven (Premise Indirect Curing Oven) selama 20 menit. Setelah dikeluarkan dan didinginkan, dilakukan finishing dan polishing.

Pada kunjungan kedua, mahkota sementara dilepas dan gigi dibersihkan. Saluran akar diirigasi dan dikeringkan dengan paper point steril kemudian pasak yang sudah disterilkan dengan alkohol $70 \%$ dicobakan ke dalam saluran akar. Pengambilan gambar radiografis dilakukan untuk konfirmasi hasil pengepasan pasak pada gigi 22. Larutan silane dioleskan pada permukaan pasak dan dibiarkan mengering. Semen resin (rely-X U 100, 3M Espe) dipersiapkan, diaduk dan dimasukkan ke dalam saluran pasak, kemudian pasak diinsersikan. Setelah itu, dilakukan pengambilan gambar radiografis untuk melihat hasil sementasi pasak pada gigi 22 . 


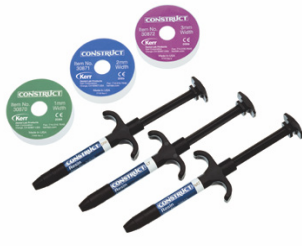

A



B

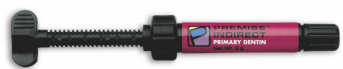

C



D

Gambar 3A. Pita fiber Construct dan Flowable resin Construct (Kerr), B. Rubber-sep (separating media), C. Premise Primary Dentin, D. Premise Indirect Curing Oven



Gambar 4. Pasak customized FRC indirect yang dibuat

Gingiva gigi 22 diretraksi dengan gingival retraction cord yang sebelumnya dicelupkan ke dalam cairan yang mengandung agen hemostatik (adrenalin) pada sulkus gingiva selama 3 menit, lalu dilepas. Pencetakan dilakukan dengan menggunakan bahan cetak double impression pada rahang atas untuk pembuatan mahkota jaket komposit dan pencetakan rahang bawah dengan irreversible hydrocolloid serta dibuat gigitan malam. Pemilihan warna mahkota jaket dilakukan menggunakan Vita Shade Guide (warna A2), setelah itu gigi 22 dipasang mahkota sementara.
Pada kunjungan ketiga, mahkota sementara dilepas, gigi 22 dibersihkan kemudian dilakukan pengepasan mahkota jaket komposit. Pemeriksaan warna, kontur, embrasur, kerapatan tepi, oklusi, dan kontak proksimalnya dilakukan pada saat try in mahkota jaket. Mahkota jaket disterilkan dalam alkohol $70 \%$ dan dikeringkan dengan semprotan angin secara perlahan. Daerah kerja diisolasi menggunakan gulungan kapas. Mahkota jaket bagian fitting surface dioles silane dan dibiarkan mengering. Sementasi mahkota jaket komposit dilakukan pada gigi 22 menggunakan semen resin (Rely $X \cup 100$, $3 M$ ESPE). Kelebihan semen dibersihkan kemudian dilakukan penyinaran selama 40 detik. Pemeriksaan oklusi dan artikulasi serta pengambilan gambar radiograf dilakukan pada saat insersi mahkota jaket. Selanjutnya pasien diminta kontrol 1 minggu kemudian.

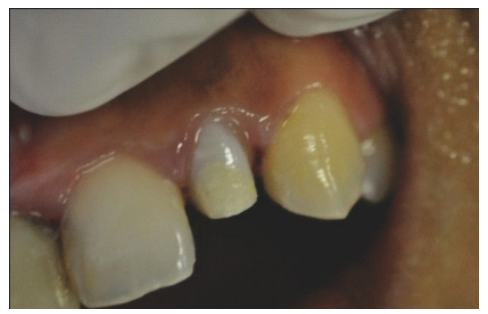

Gambar 5. Sementasi pasak menggunakan semen resin

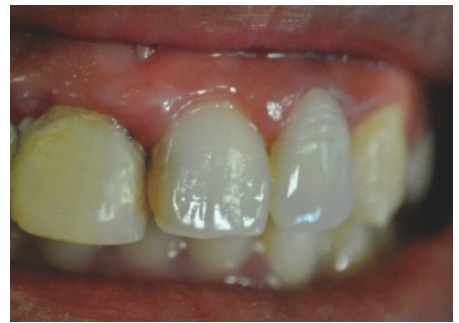

Gambar 6. Mahkota jaket komposit setelah diinsersikan pada gigi 22

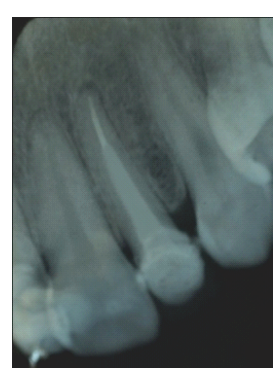

Gambar 7. Gambaran radiograf gigi 22 setelah sementasi mahkota jaket komposit 


\section{PEMBAHASAN}

Kegagalan perawatan endodontik lebih sering terjadi karena restorasi daripada perawatan endodontik itu sendiri. ${ }^{1}$ Dislodgement dan fraktur akar merupakan penyebab dari kegagalan restorasi inti pasak. ${ }^{5}$ Oleh karena itu, penting untuk merencanakan perawatan sehubungan dengan teknik endodontik dan keberhasilan restorasi. ${ }^{1}$

Fraktur akar merupakan salah satu kegagalan sistem inti pasak. Tujuan utama merestorasi gigi pasca PSA adalah membangun suatu desain monoblok, yang dapat mendistribusikan tekanan oklusal serta menjaga struktur gigi jika terjadi kegagalan selama tekanan oklusal atau trauma. Pasak logam tradisional memiliki modulus elastisitas 10 kali lebih besar daripada dentin normal sehingga dapat menyebabkan konsentrasi tekanan pada akar yang rigid dan menyebabkan separasi pasak atau kegagalan restorasi. Transmisi tekanan oklusal pada inti logam dapat memfokuskan tekanan di regio spesifik pada akar sehingga dapat menyebabkan fraktur akar. ${ }^{5}$

Kestabilan inti dan retensi pasak merupakan faktor penting dalam usaha mencegah kegagalan restorasi gigi pasca PSA. Pasak yang ideal seharusnya dapat menggantikan struktur gigi yang hilang serta memberikan retensi dan dukungan pada inti sehingga memungkinkan terjadinya retensi pada restorasi dan distribusi tekanan oklusal yang dapat mencegah fraktur. Pasak customized fiber reinforced composite memanfaatkan anatomi internal, area permukaan dan iregularitas untuk meningkatkan ikatan antara dentin dan pasak sehingga dapat meningkatkan integritas struktur dari dentin radikular yang tersisa dan meningkatkan retensi serta resistensi. ${ }^{5}$

Restorasi resin komposit indirek, menawarkan beberapa kelebihan dibandingkan restorasi resin komposit direk. Pada restorasi direk, polymerization shrinkage terjadi dalam matriks resin, ketika resin komposit dipolimerisasi. Shrinkage tersebut akan menyebabkan celah tepi diantara dentin dan permukaan resin komposit. Jika resin komposit dipolimerisasi di laboratorium dengan cahaya, panas atau metode lain (metode indirek), shrinkage yang terjadi minimal karena derajat polimerisasinya lebih tinggi daripada hanya dengan cahaya saja. Properti fisiknya juga meningkat sehingga menghasilkan restorasi yang lebih kuat dan lebih tahan lama. Teknik indirek juga dapat membentuk kontur dan kontak interproksimal yang lebih baik. ${ }^{8}$

Pada kasus ini, pasak fiber reinforced composite indirect dibuat customized pada saluran pasak karena ukuran saluran pasak yang sangat lebar sehingga pasak fiber prefabricated tidak diindikasikan. Pasak customized fiber reinforced composite indirect menggunakan pita fiber construct (Kerr) dan Premise Indirect Composite (Kerr). Pita fiber construct merupakan fiber polyethylene yang memiliki kekuatan ultra tinggi yang dilapisi oleh plasma dan diperkuat oleh unfilled resin. ${ }^{9}$ Premise Indirect merupakan kombinasi partikel filler prepolymerized yang berukuran besar, 0,4 micron structural filler, small silica nanoparticle yang menyebabkan ukuran fillemya lebih tinggi sehingga dapat meningkatkan properti fisik, meningkatkan permukaan yang mengkilap, dan mengurangi polymerization shrinkage. Pasak dipolimerisasi menggunakan Light Curing Unit dan oven (Premise Indirect Curing Oven) dengan suhu $138^{\circ} \mathrm{C}$ serta tekanan nitrogen $60 \mathrm{psi} / 4.13$ Barpressure. Trimodal curing (cahaya, panas dan tekanan) ini menghasilkan polimerisasi lebih dari $98 \%$, sedangkan cahaya hanya akan mencapai 60 $70 \%{ }^{8}$

Pasak customized fiber reinforced composite indirect dibuat sesuai dengan bentuk anatomi saluran akar. Oleh karena itu, hanya dibutuhkan selapis tipis semen resin sehingga dapat mendistribusikan tekanan oklusal yang ditransmisikan pada gigi, mengurangi efek pengerutan polimerisasi dan mengurangi dimensi bubble pada semen itu sendiri. ${ }^{1}$

\section{KESIMPULAN}

Gigi non vital pasca PSA dengan saluran akar yang lebar dan dinding saluran akar yang tipis, dapat direstorasi dengan pasak customized fiber reinforced composite indirect. 


\section{SARAN}

Pasak customized fiber reinforced composite indirect membutuhkan kecermatan yang tinggi dalam pembuatannya supaya mendapatkan hasil yang diharapkan.

\section{DAFTAR PUSTAKA}

1. Neha D, Sunil D. An esthetic endeavour for compromised anterior teeth - A case report. Bangladesh Journal of Medical Science. 2013; 12(01): 100-3.

2. McComb D. Restoration of Endodontically Treated Tooth. Ensuring Countinuing Trust DISPATCH. 2008; 1-20

3. Garg N, Garg A. Textbook of Endodontics. $1^{\text {st }}$ ed. New Delhi: Jaypee Brothers Medical Publishers, 2008 ; 324

4. Arora V, Nikhil V, Suri NK, - Arora P. Reinforcement of flared root canals with fiber post and auxillary prepolymerised nanohybrid composite posts: a clinical report. International
Journal of Innovative Research in Science. 2013; 7210-3.

5. Terry DA. Design principles for the direct fiber-reinforced composite resin post-andcore system. Contemporary esthetics and restorative practice. 2003; 22-32.

6. Teixera CS, Silva-Sousa YTC, Sousa-Neto MD. Bond strength of fiber post to weakened roots after resin restoration with different light curing times. JOE. 2009; 35(7); 1034-9.

7. Schwartz RS. Restoration of Endodontically Treated Teeth. 2004. Diakses dari www.aae.org. Diunduh tanggal 28 Oktober 2014.

8. Aschheim KW. Esthetic Dentistry: A clinical approach to techniques and materials. $3^{\text {rd }} \mathrm{ed}$, Elsevier Mosby; 2015; 109-10.

9. Juloski J, Beloica M, Goracci C, Chieffi N, Giovannetti A, Vichi A, Vulicevic ZR, Ferrari $M$, al. Shear bond strength to enamel and flexural strength of different fiber reinforced composites. The journal of adhesive dentistry. 2012; 14 (10) (X); 1-8. 